\title{
TÉCNICA PIANÍSTICA E COORDENAÇÃO MOTORA: RELAÇÕES INTERDISCIPLINARES COM VISTAS À APRENDIZAGEM MOTORA ${ }^{1}$
}

\author{
Maria Bernardete Castelan Póvoas², Vânia Eger Pontes ${ }^{3}$.
}

Palavras-chave: Técnica pianística. Coordenação motora. Interdisciplinaridade.

Resumo: Esta investigação faz parte da pesquisa Ação Pianística e Coordenação Motora: Relações Interdisciplinares, na qual propõe-se realizar um estudo relacionando aspectos da técnica pianística com o fator do desempenho coordenação motora, estabelecendo-se conexões entre questões técnico-instrumentais e argumentos de áreas como ergonomia, cinesiologia e biomecânica.

\section{Introdução}

Para um melhor aproveitamento e aprimoramento do movimento durante a ação pianística, realizou-se um estudo sobre técnica pianística e coordenação motora e foram selecionados assuntos ligados ao conceito de aprendizagem motora para um maior aprofundamento, sendo eles: classificação de habilidades motoras, processo de aprendizagem e tipos de prática. Além dos objetivos de estudo ja citados, neste trabalho primou-se também por realizar correspondências entre o material estudado e a prática pianística. Utilizando-se $o s$ ciclos de movimento, verificou-se se este recurso técnico-pianístico de flexibilização do movimento proposto por Póvoas (1999) integraria em suas estratégias conceitos relacionados à coordenação motora e se poderia ser classificado como um recurso técnico-instrumental interdisciplinar. Dentre as ações inseridas neste trabalho,foram realizados levantamento e aplicação de exercícios para o desenvolvimento de uma maior consciência do membro superior; pesquisa bibliográfica em áreas selecionadas, visando o favorecimento do estudo ao piano através da interdisciplinaridade. Os bolsistas da presente pesquisa, sob orientação, fizeram uso do princípio de relação impulso-movimento - ciclos de movimento (Póvoas, 1999), com o intuito de otimizar o estudo pianístico, visando um trabalho mais eficiente em função do resultado sonoro pretendido e, paralelamente a este estudo, fez-se conexões com a bibliografia pesquisada.

\footnotetext{
${ }^{1}$ Projeto de Pesquisa CEART/UDESC.

${ }^{2}$ Orientadora e coordenadora do projeto: Profa. Dra. Maria Bernardete Castelan Póvoas, Professora do Depto de Música, CEART/UDESC - Av. Madre Benvenuta, 1907 - CEP 88035-001 Florianópolis-SC.

${ }^{3}$ Bolsista de iniciação científica do Sistema PIBIC/CNPQ - UDESC, aluna do Curso de Bacharelado em piano, CEART/UDESC.
} 


\section{Resultados}

A partir da seleção de situações técnico-musicais estudadas, mostra-se a seguir um exemplo de aplicações de procedimentos pesquisados em trecho em que estabeleceram-se correlações interdisciplinares que podem auxiliar na avaliação risco - benefício quando de sua utilização.

O trecho referente à Figura 1 mostra uma passagem musical que consiste de distâncias entre eventos ${ }^{4}$ de oitavas e acordes a serem percorridas através da realização de movimentos rápidos, movimentos estes considerados complexos já que possuem várias mudanças de direção em um curto espaço de tempo. Para mudar a direção de um movimento com trajetória em linha reta, a única opção é interrompê-lo, vê-se que não há como manter o movimento regular. O princípio de relação impulso-movimento - ciclos de movimento (Póvoas, 1999) foi utilizado como auxílio neste trecho, dentre outros. Observando-se a Figura 01 estão as setas, seus sentidos côncavo e convexo que orientam a trajetória do movimento por uma inflexão do punho. Para a realização da trajetória ilustrada pela seta convexa entre o primeiro evento e o segundo evento o punho, como condutor do movimento, deve iniciar de uma posição mais baixa ou paralela ao teclado e, por um impulso que serve de trampolim, atingir o segundo evento. Deste segue, por um movimento no sentido côncavo gradativo na medida em que realiza o(s) evento(s) dentro da linha (seta), até o quarto evento, onde retoma a posição inicial, e assim por diante.

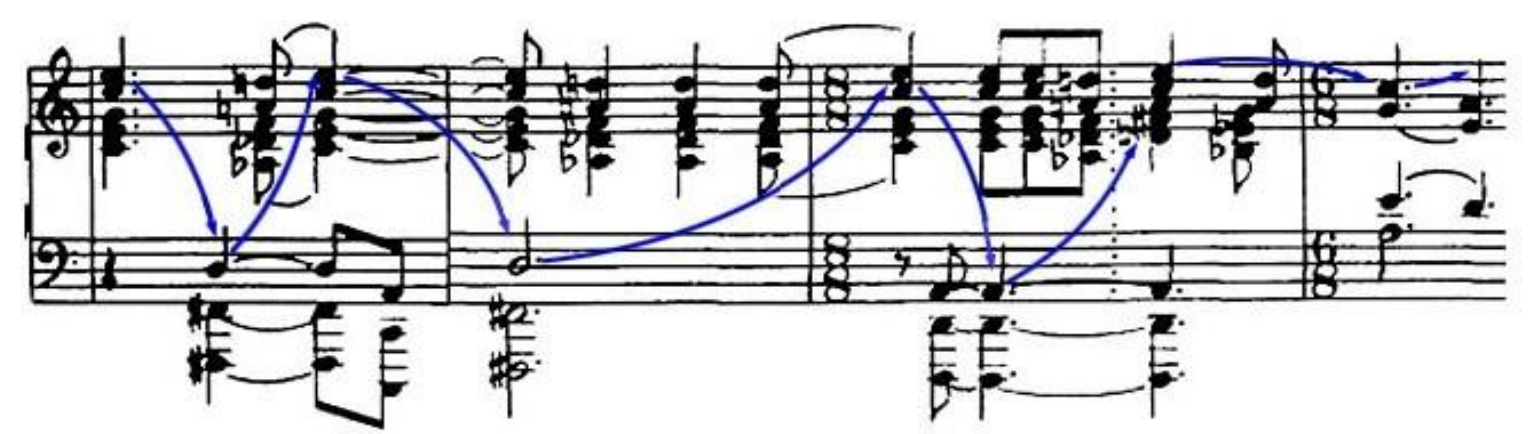

Figura 01 - Aplicação do princípio proposto por Póvoas (1999), no trecho referente aos compassos [142] a [145] do Allegro marcato.

Fonte: GINASTERA, 1954, p. 05 e 06.

O uso do gesto de deslocamento do punho no sentido parabólico é um recurso que permite a mudança de direção em uma trajetória sem a interrupção do movimento, realizandoo com maior regularidade. Com este tipo de direcionamento da técnica tem-se uma maior

${ }^{4}$ Evento: notas que ocorrem simultaneamente no sentido vertical. 
consciência do controle cinestésico, que produz informações sobre "a posição das partes do corpo relativas umas às outras; a posição do corpo no espaço; os movimentos corporais; a natureza dos objetos com os quais os corpo estabelece contato". (HAYWOOD \& GETCHELL, 2004, p. 187).

\section{Discussão}

\section{Coordenação Motora}

A coordenação do movimento é uma "ordenação, organização de ações motoras no sentido de uma meta determinada, bem como um objetivo" (FOSTER, 1902 apud MEINEL, 1987, p.3). De acordo com Turvey (1990) apud Magill (2000, p. 38), “coordenação é a padronização dos movimentos do corpo e dos membros relativamente à padronização dos eventos e objetos do ambiente". Tocar piano subentende a realização de uma série de movimentos complexos que devem acontecer de forma organizada, em concordância com alguma referência ou texto musical. Há uma interação entre a realização dos movimentos do pianista e à mecânica do piano.

O desenvolvimento das habilidades motoras dos diversos tipos

- para atender às exigências musicais de uma partitura consiste, principalmente, em melhorar a rapidez e a precisão com que o sistema nervoso central coordena a atividade. (KAPLAN ,1987, p. 20).

A coordenação motora está ligada a uma séria de fatores determinantes na realização do movimento, "inúmeros fatores e processos isolados [...] atuam conjuntamente num movimento simples", (MEINEL, 1987, p. 03), o mesmo autor acrescenta que

na anatomia funcional como na cinesiologia são compreendidos por coordenação de movimento, em primeiro lugar, ordenações comprovadas na atividade de cada músculo e de grupos musculares. A biomecânica considera sob o conceito de coordenação os parâmetros codeterminantes do decurso do movimento, sobretudo os diferentes impulsos de força a serem coordenados na ação motora. (MEINEL, 1987, p. 02). 


\section{Aprendizagem motora}

De acordo com Shumway-Cook \& Woollacott (2003) a prendizagem é definida como a aquisição do conhecimento ou da capacidade. Aprendizagem motora diz respeiro ao ganho relativamente permanente de habilidades associados à prática ou à experiência ( Schmidt \& Lee 1999 apud Haywood \& Getchell, 2004).

De acordo com Shumway-Cook \& Woollacott (2003, p.02), o corpo humano realiza uma série de movimentos, que emergem de "uma integração entre o indivíduo, a tarefa e o ambiente" e estes movimentos são coordenados pelo controle motor, entendido como a capacidade de orientar ou regular os mecanismos essencias na realização do movimento.

O processo de aprendizagem, em seu decorrer (Magill, 2000), pode ser observado de acordo com quatro características gerais do desempenho: aperfeiçoamento, consistência, persistência e adaptabilidade. - O aperfeiçoamento trata de situações em que a habilidade, se realizada corretamente, ao longo do tempo apresenta-se aperfeiçoada. É importante salientar que se a aprendizagem da habilidade for ineficiente ela pode piorar ao longo do tempo; - a consistência, nela os níveis de desempenho melhoram mais rapidamente de uma tentativa para outra à medida em que a aprendizagem avança, não como no início em que há mais variações nos níveis de consistência; - a persistência, de acordo com Magill (2000) é a terceira característica geral observada na aprendizagem, onde o desempenho aprimorado é marcado por quantidade maior de persistência, "a capacidade de desempenho melhorada se estende por períodos maiores"(p.137); - a adaptabilidade mostra que cada vez que desempenhamos uma tarefa as condições, sejam emocionais ou ambientais, estão diferentes, por mínimas que sejam e adaptamo-nos a elas e o desempenho continua sendo bem sucedido. Como se pode perceber, além da dedicação do indivíduo, a aprendizagem de uma nova habilidade depende de diversos fatores, que podem ser observados e aperfeiçoados para o sucesso da tarefa pretendida, seja ela qual for.

No processo de aprendizagem pianística são visíveis as transformações das características comentadas no parágrafo anterior, na prática pianística busca-se constantemente o aperfeiçoamento e um desempenho consistente. Devido à dificuldade de deslocar seu instrumento pessoal à locais de recital, o pianista, ao decorrer de sua carreira, toca em pianos que apresentam variações mecânicas entre si. Este é um exemplo prático de adaptabilidade. Mesmo que o estado de algum instrumento dificulte a execução de algumas passagens, o profissional adapta-se e seu desempenho não necessariamente será prejudicado, 
isto dependerá também, em parte, da consistência em seu processo de aprendizagem.

Classificaçao de habilidades motoras

Define-se como habilidade motora habilidades que exigem movimento voluntário corporal para atingir uma meta (Magill 2000). Os tipos de habilidades são muitas e diversas, por exemplo, tocar piano, acertar a bola com a raquete no jogo de tênis, arremessar uma bola no beisebol, dançar, dirigir um carro, andar de bicicleta, dentre outras. Além da habilidade, outros fatores influenciam no controle motor, o fator afetivo e também cognitivo, capacidade de concentração e de raciocínio. Magill (2000) relata que muitos enfoques foram desenvolvidos para classificar as habilidades motoras, mas considera quatro deles: precisão do movimento, caráter bem definido dos pontos iniciais e finais, estabilidade do meio ambiente e controle por feeedback ( retroinformação).

Schimidt \& Wrisberg (2001) explicam três esquemas classificação de habilidades os quais adotaremos para a explanação deste assunto. $\mathrm{O}$ primeiro esquema tem como base o modo como o movimento é organizado. Este primeiro sistema de classificação engloba por sua vez, tipos de habilidades denominadas habilidade discreta, habilidades seriadas $e$ habilidades contínuas. A habilidade discreta caracteriza-se por ser geralmente de breve duração e ter início e fim bem definidos. As habilidades seriadas requerem um tempo mais longo, são ações mais complexas formadas a partir de uma série de habilidades discretas, neste caso a ordem dos elementos pode ser determinante no êxito da realização da tarefa. As Habilidades contínuas caracterizam-se por serem geralmente repetitivas, o que acaba por sugerir que não tenham início e fim definidos, a exemplo da natação ou do pedalar de uma bicicleta, pois que dependem de circunstâncias no momento do seu início e final (variáveis).

O segundo esquema trata de habilidades classificadas pela importância relativa dos elementos motores e cognitivos. "Em resumo, uma habilidade cognitiva é aquela que enfatiza "saber o que fazer", enquanto uma habilidade motora enfatiza, principalmente, a "execução correta". (SCHIMIDT \& WRISBERG, 2001, p.21). Um exemplo dado pelos autores citados é o do jogo de xadrez em que a velocidade com que se move a peça (habilidade motora) não tem o mesmo grau de importância quanto à decisão de estratégia adotada pelo jogador (habilidade cognitiva). De acordo com este sistema, o modo mais apropriado de classificação das habilidades motoras é considerar quanto de cada elemento, motor e cognitivo, contribui para a execução da tarefa. Na prática pianística observamos diferentes situações envolvendo

DAPesquisa, Florianópolis, v.2, n.4, p. 472-479, 2007. 
estas duas habilidades. Quando não se está seguro com relação às notas ou estrutura de uma certa passagem musical, vê-se que a habilidade cognitiva interfere na habilidade motora. $\mathrm{O}$ executante não poderá realizar o movimento cosistentemente já que não tem certeza da direção ou do percurso do movimento, ou seja, do objetivo de sua trajetória.

O terceiro esquema de classificação leva em conta o nível de previsibilidade ambiental. Neste esquema trata-se de habilidades fechadas e abertas. As habilidades fechadas são aquelas realizadas em ambientes estáveis e previsíveis, como em situações em que se realizam séries de ginástica ou se nada sozinho na raia de uma piscina. Já nas habilidades abertas, o ambiente em que a ação é realizada é imprevisível e variável, como em situações de um jogo de tênis em que se golpeia a bola após seu quique. Neste caso "o executante deve utilizar os processos de precepção, reconhecimento de padrão e tomada de decisão para ajustar o movimento, geralmente em uma pequena quantidade de tempo". (SCHIMIDT \& WRISBERG, 2001, p. 22). Na prática pianística este tipo de habilidade é comum, pois em muitos momentos tomam-se decisões em um curto espaço de tempo sem que haja interrupção da música. Um exemplo seria o de momentos em que o instrumentista tenha um suposto lapso de memória, ele precisa dar continuidade à música, seja retomando de outro trecho da partitura ou improvisando.

\section{Tipos de Prática}

Com o treinamento de determinada habilidade, pretende-se desenvolver a habilidade de tocar piano e, para isto, várias tarefas devem ser realizadas até obter determinados graus de prática necessários na realização da habilidade. "O problema que confronta professores [...] é como sequiênciar a prática de uma variedade de tarefas dentro de uma sessão, a fim de maximizar a aprendizagem.” (SCHIMIDT \& WRISBERG, 2001, p. 247). Dentre inúmeros estudos existentes sobre este tema, considerar-se-á duas escalas ou seqüênciamentos de prática a partir de informações encontradas em Schimidt \& Wrisberg (2001), a prática em blocos e a prática randômica. Estas influem na aprendizagem e seus efeitos serão aqui comentados. Suponhamos que um indivíduo preste-se a aprender duas ou mais tarefas razoavelmente diferentes (como parafusar um parafuso, recortar uma folha de papel e abrir uma lata com abridor), na prática em blocos uma situação comum é a de treinar repetidamente a mesma tarefa. Os objetivos são de fixação, refinamento e muitas vezes o indivíduo só passa para a próxima tarefa quando a anterior já pode ser realizada com o desempenho satisfatório.

Já na prática randômica realizam-se diferentes tarefas sem ordem específica, evitandoDAPesquisa, Florianópolis, v.2, n.4, p. 472-479, 2007. 
se ou diminuindo o número de repetições consecutivas de uma tarefa, "a ordem de treinamento de um número de diferentes tarefas é interligada, ou combinada, durante os períodos de prática, [...] os aprendizes [...] em casos mais extremos nunca desenvolvem a mesma tarefa duas vezes seguidas." (SCHIMIDT \& WRISBERG, 2001, p. 247).

No estudo do piano podem ser observados estes dois tipos de prática entre os estudantes, porém, com base em estudo e orientações, percebe-se que a prática randômica é a mais eficaz. (Schimidt \& Wrisberg 2001). Com relação à aprendizagem, a prática randômica mostra-se mais eficiente do que a prática em blocos, a qual acarreta em um melhor desempenho apenas na prática inicial da tarefa. No caso da aprendizagem e estudo pianístico, a prática em blocos que sugere inúmeras repetições é usada, mas sugere-se que sejam tomados certos cuidados. Há risco de ineficiência no desempenho técnico instrumental, já que a atividade de tocar piano envolve diversas estruturas corporais e todo movimento realizado repetidamente por um longo intervalo de tempo ocasiona gasto de energia, havendo risco de o indivíduo entrar em estado de fadiga muscular devido ao fator peso e ao tamanho da estrutura segmentar envolvida neste contexto: dedos e mãos. A alternância de tarefas mostra-se eficiente, pois, possivelmente, haverá utilização de outras posições e movimentos corporais de acordo com a variedade ou não de elementos textuais contidos na partitura.

\section{Conclusão}

A utilização do princípio de relação impulso-movimento - ciclos de movimento (Póvoas, 1999) auxiliou no sentido de desenvolver o controle motor, como em situações de precisão em passagens que exigem saltos com trajetórias longas entre eventos, aumentando as possibilidades sucesso na execução pianística, já que possibilita uma maior percepção da posição dos membros superiores em relação teclado.

A partir das informações pesquisadas e conexões traçadas entre as áreas do conhecimento selecionadas, conclui-se que tocar piano é uma habilidade que pode ser auxiliada a partir de diversas vertentes. Na aprendizagem motora não subentende-se que serão aprendidas apenas habilidades de forma correta, movimentos e hábitos incorretos também são incorporados à tarefas diárias realizadas pelo ser humano. Por isto, há uma série de fatores a serem observados, tais como a postura corporal, a eficiência do método utilizado para a aprendizagem, o meio em que a tarefa deve ser realizada ou aprimorada e outros demais fatores tais como a quantidade de força empregada durante o treinamento, intervalos entre períodos de prática ao instrumento, entre outros.

DAPesquisa, Florianópolis, v.2, n.4, p. 472-479, 2007. 
Na ação pianística tem-se a prática randômica como auxiliar na aprendizagem, além de auxiliar na manutenção das estruturas envolvidas, previne fadiga ou possíveis lesões. Um maior contato com conceitos e pressupostos básicos de áreas que estudam a coordenação motora, aprendizagem motora, técnica pianística e demais áreas que tratam do movimento possibilitam um maior entendimento das habilidades desenvolvidas por pianístas e fornece subsídios para o aperfeiçoamento do desempenho.

Referências Bibliográficas

GINASTERA, Alberto. Sonata Para piano n.1. op. 22. Buenos Aires: Barry \& Cia.1954. HAYWOOD, Kathleen,; GETCHELL, Nancy. Desenvolvimento motor ao longo da vida. 3. ed. Porto Alegre: Artmed, 2004.

KAPLAN, José Alberto. Teoria da Aprendizagem Pianística. Porto Alegre: Movimento, 1987.

MAGILL, Richard. Aprendizagem Motora: conceitos e Aplicações. São Paulo: Edgard Blücher, 2000.

MEINEL, Curt. Motricidade I: Teoria da Motricidade Esportiva sob o Aspecto Pedagógico. São Paulo: Ao Livro Técnico, 1987.

PÓVOAS, Maria Bernardete Castelan Póvoas. Princípio da Relação e Regulação do Impulso-Movimento. Possíveis Reflexos na Ação Pianística. 236p. 1999.Tese (Doutorado em Música) - Universidade Federal do Rio Grande do Sul, Porto Alegre, 1999.

Ação pianística, desempenho e controle do movimento - uma perspectiva interdisciplinar. In: Anais do III Simpósio de Cognição e Artes Musicais. Salvador: EDUFBA, 2007. p 540-548.

SCHMIDT, Richard A.; WRISBERG, Craig A. Aprendizagem e performance motora: uma abordagem da aprendizagem baseada no problema. 2. ed. Porto Alegre: Artmed, 2001.

SHUMWAY-COOK, Anne; WOOLLACOTT, Marjorie H. Controle motor: teoria e aplicações práticas. 2. ed. Barueri: Manole, 2003. 